\title{
Neurological condition in 18-month-old children perinatally exposed to polychlorinated biphenyls and dioxins
}

\author{
Marcel Huisman*a , Corine Koopman-Esseboom ${ }^{\mathrm{b}}$, \\ Caren I. Lanting ${ }^{a}$, Cornelis G. van der Paauw", \\ Louis G.M.Th. Tuinstra ${ }^{d}$, Václav Fidler ${ }^{e}$, \\ Nynke Weisglas-Kuperus ${ }^{b}$, Pieter J.J. Sauer ${ }^{b}$, E. Rudy Boersma ${ }^{a}$, \\ Bert C.L. Touwen ${ }^{f}$ \\ Department of Obstetrics and Gynaecology, Nutrition and Development Unit, University of Groningen. \\ Oostersingel 59, 9713 EZ Groningen, The Netherlands \\ 'Department of Pediatrics, Erasmus University and University Hospital/Sophia Children's Hospital, \\ Rotterdam, The Netherlands \\ 'TNO Nutrition and Food Research Institute, Zeist, The Netherlands \\ ${ }^{d} D L O$ State Institute for Quality Contral of Agriculture Products, Wageningen, The Netherlands \\ -Department of Health Sciences, Epidemiology and Statistics Unit, University of Groningen, \\ Groningen, The Netherlands \\ iDepartment of Medical Physiology, Developmental Neurology, University Hospital Groningen. \\ Groningen, The Netherlands
}

Received 21 April 1995; revision received 4 July 1995; accepted 15 July 1995

\begin{abstract}
The neurological optimality of 418 Dutch children was evaluated at the age of 18 months, in order to determine whether prenatal and breast milk mediated exposure to polychlorinated biphenyls (PCBs) and dioxins affected neurological development. Half of the infants were breast-fed, the other half were formula-fed. PCB concentrations in cord and maternal plasma were used as a measure of prenatal exposure to PCBs. To measure postnatal exposure, PCB and dioxin congeners were determined in human milk and in formula milk. After adjusting for covariates, transplacental PCB exposure was negatively related to the neurological condition at 18 months. Although greater amounts of PCBs and dioxins are transferred via nursing
\end{abstract}

\footnotetext{
* Corresponding author, Tel.: +31 503 613090; Fax: +31 503613012 .
} 
than via placental passage, an effect of lactational exposure to PCBs and dioxins could not be detected. We even found a beneficial effect of breast-feeding on the fluency of movements. We conclude that transplacental PCB passage has a small negative effect on the neurological condition in 18-month-old toddlers.

Keywords: Polychlorinated biphenyls; Dioxins; Neurological development; Toddlers; Human milk

\section{Introduction}

Polychlorinated biphenyls (PCBs) and dioxins are widespread toxic environmental pollutants. Until the late-1970s, PCBs were produced for use as fire retardants, plasticizers, dielectric fluids in capacitors and transformers, and hydraulic fluids. There is a total number of 209 possible PCB congeners, which all differ in their degree of chlorination and the position of the chlorine atom. PCBs can be divided into planar and non-planar PCBs. The planar PCBs resemble the dioxins to the largest extent. Dioxins are unwanted byproducts of thermal and industrial processes, consisting of 75 possible polychlorinated dibenzo-p-dioxin congeners and 135 possible polychlorinated dibenzofuran congeners. Due to a high persistency, they can be detected in food products of animal origin, human adipose tissue and blood [1]. Once entered into the food-chain, these lipophilic compounds are bioconcentrated exposing human beings who continuously absorb very small doses. Substantially greater amounts of PCBs are transferred via nursing than as a result of placental passage in both animals $[2,3]$ and humans [4,5]. Infant formulae contain only lipids of a vegetable origin with a negligible content of PCBs and dioxins. Since breast-fed children receive considerably more of these compounds compared to those formulafed, controversy exists over whether breast-feeding should be encouraged.

Rogan et al. showed that higher levels of transplacental exposure to PCBs were associated with hypotonicity and hyporeflexia in neonates [6]. We partly confirmed these results in our study concerning neonates. The combination of a high prenatal and a high lactational exposure during the first 2 weeks after birth was associated with an increase in the prevalence of neonatal neurological non-optimality and a higher incidence of hypotonia [5].

So far, the effects of PCB exposure have been evaluated as regards mental and psychomotor development [7]. We now report on the relationship between prenatal exposure to PCBs and lactational exposure to PCBs and dioxins and the neurological condition at 18 months.

\section{Subjects and methods}

From June 1990 until June 1992, pregnant women were recruited for the study in Groningen and Rotterdam. The planned sample size was 100 breast-feeding and 100 formula-feeding mothers in each centre. The women were approached between the 32nd and 34th week of pregnancy and provisionally assigned, on the basis of their 
intention, to the formula-feeding or the breast-feeding group. Women suffering from serious illnesses or complications during pregnancy and delivery were excluded, as were mothers having an instrumental delivery. From the provisional breast-feeding group, only the mothers were included in the study who breast-fed their infants for at least 6 weeks. Formula milk from a single batch (Almiron M2; Nutricia N.V., The Netherlands) was used in the formula-feeding group. Approval was obtained from the ethics committees of the University Hospitals in both centres.

Social, obstetrical, and perinatal circumstances were recorded by means of a questionnaire with 72 representative items. The number of items that fulfilled predefined optimality criteria [8] was used as an obstetrical optimality score [9]. All newborns underwent a neurological examination according to Prechtl [10].

A maternal blood sample was taken in the last month of pregnancy and cord blood was collected immediately after birth. Plasma samples were analyzed for four non-planar PCB congeners 118, 138, 153, and 180 only. Plasma has a relatively low fat content compared to human milk and too large a volume of blood would be needed to measure all the PCB and dioxin congeners, such as were analyzed in human milk. The sum of the concentrations of the four PCB congeners 118, 138, 153, and 180 in plasma (i.e. $\Sigma \mathbf{S C B}_{\text {maternal }}$ and $\Sigma \mathrm{ICB}_{\text {cord }}$, respectively) was used as a measure of prenatal exposure to PCBs. Postnatal exposure to PCBs and dioxins via breast milk was reflected by the levels of these compounds in a 24-h sample taken in the second week after delivery. Contents of 17 2,3,7,8-substituted polychlorinated dibenzo-p-dioxins and dibenzofurans, three planar PCBs, and 23 non-planar PCB congeners were determined in breast milk fat as well as in the formula milk fat. In order to express the toxicity of the mixture of compounds in breast milk and in the artificial formula, the toxic equivalency approach was used [11]. With this approach, the relative toxicity (TEQ) of each congener towards the most toxic dioxin congener was calculated. By adding up the TEQs of all congeners, the total TEQ value was obtained (in ng TEQ/kg milk fat). The sampling, analytical, and data processing procedures have previously been described [5].

At 18 months of age, the neurological condition was assessed using an age-specific neurological examination [12]. This technique focuses on the observation of motor functions (grasping, sitting, crawling, standing, and walking) in a standardized free field situation $[13,14]$. On the basis of this examination each toddler was classified as normal, mildly abnormal, or abnormal. The classification 'abnormal' implies the presence of an overt circumscript neurological syndrome, which usually leads to a handicap in daily life, such as cerebral palsy. 'Mildly abnormal' signifies the presence of mild signs which do not necessarily lead to a handicapping condition, e.g. slight asymmetries, or mild hypo-, and hypertonia. The neurological findings were also evaluated in terms of optimality [8]. A list of 57 neurological items was composed, for each of which an optimal range was defined (Appendix). By giving a point for each item meeting the criteria for optimality, the neurological optimality score was calculated by counting the number of optimal items. It must be emphasized that optimality is not identical with normality, and that a reduced optimality not always mean abnormal [8]. Special attention was given to the quality of movements in terms of fluency. Fluency of motility has been shown to be an indicator for the integrity 
Table 1

Characteristics of the study group

\begin{tabular}{|c|c|c|}
\hline Variable & Breast-fed & Formula-fed \\
\hline $\begin{array}{l}\text { Number of children } \\
\text { Neonatal neurological diagnosis }\end{array}$ & 209 & 209 \\
\hline Normal & $197(94)$ & $197(94)$ \\
\hline Mildly abnormal & $10(5)$ & $10(5)$ \\
\hline Abnormal & $2(1)$ & $2(1)$ \\
\hline \multicolumn{3}{|l|}{ Neurological diagnosis at 18 months } \\
\hline Normal & $205(98)$ & $203(97)$ \\
\hline Mildly abnormal & $3(1)$ & $6(3)$ \\
\hline Abnormal & $1(1)$ & $0(0)$ \\
\hline \multicolumn{3}{|l|}{ Neurological optimality score at 18 months } \\
\hline $\begin{array}{l}\mathbf{P}_{\mathbf{S}}, \mathbf{P}_{\mathbf{5 0}}, \mathbf{P}_{\mathbf{9 5}} \\
\text { Fluency cluster score }\end{array}$ & $41,48,53^{*}$ & $40,47,52$ \\
\hline Mean \pm S.D. & $10.2 \pm 1.6^{*}$ & $9.5 \pm 1.7$ \\
\hline \multicolumn{3}{|l|}{$\mathrm{PCB} /$ dioxin exposure $\left(\mathrm{P}_{5}, \mathrm{P}_{50}, \mathrm{P}_{95}\right)$} \\
\hline $\operatorname{LPCB}_{\text {cord }}(\mu g /)$ & $0.20,0.43,0.99 *$ & $0.16,0.34,0.80$ \\
\hline $\mathrm{IPCB}_{\text {maternal }}(\mu \mathrm{g} / \mathrm{l})$ & $1.1,2.2,4.0^{*}$ & $0.95,1.9,3.6$ \\
\hline$T E Q_{P C B}$ (ng TEQ/kg milk fat) & $17,33,61^{*}$ & Below detection limit \\
\hline$T E Q_{\text {dioxin }}$ (ng TEQ/kg milk fat) & $15,29,52^{*}$ & Below detection limit \\
\hline \multicolumn{3}{|l|}{ Education } \\
\hline Mother, higher education ${ }^{a}$ & $132(63)^{*}$ & $50(24)$ \\
\hline Father, higher education & $130(62)^{*}$ & $64(31)$ \\
\hline \multicolumn{3}{|l|}{ Duration of exclusive breast-feeding (weeks) } \\
\hline$\underset{\text { Parity }}{P_{5}, P_{50}, P_{95}}$ & $6,13,31$ & 0 \\
\hline First-born & $107(51)$ & $94(45)$ \\
\hline \multicolumn{3}{|l|}{ Gender } \\
\hline Male & $118(57)$ & $107(51)$ \\
\hline \multicolumn{3}{|l|}{ Obstetrical optimality score } \\
\hline $\begin{array}{c}P_{5}, P_{50}, P_{95} \\
\text { Birth weight (kg) }\end{array}$ & $59,65,69^{*}$ & $57,64,68$ \\
\hline Mean \pm S.D. & $3.54 \pm 0.46$ & $3.49 \pm 0.43$ \\
\hline \multicolumn{3}{|l|}{ Maternal weight (kg) } \\
\hline Mean \pm S.D. & $64 \pm 9$ & $66 \pm 11$ \\
\hline \multicolumn{3}{|l|}{ Smoking } \\
\hline Mother, not smoking during pregnancy & $175(84)^{*}$ & $135(65)$ \\
\hline Father, not smoking during pregnancy & $126(60)$ & $117(56)$ \\
\hline \multicolumn{3}{|l|}{ Alcohol consumption during pregnancy } \\
\hline Mother, no alcohol consumption & $131(63)^{*}$ & $171(82)$ \\
\hline
\end{tabular}

Percentages in parentheses; EPCB: sum of the levels of PCB 118, 138, 153, 180; TEQPCB: toxic equivalent for planar, mono-ortho, and di-ortho $P C B s ;$ TEQ $_{\text {dioxin: }}$ toxic equivalent for dioxins.

${ }^{2} H i g h e r$ level secondary school or professional/university training.

"Significantly different from the formula-fed group $(P \leq 0.05)$. 
of brain function in fetuses and prematures [15,16]. The quality of movements during prehension, sitting, crawling, standing, and walking was scored separately as a fluency cluster (Appendix). The neurological examinations were carried out in Groningen by M.H. and in Rotterdam by C.K.E. after extensive training. The examiners were aware of the feeding status but not of the results of the chemical analyses of the plasma and milk samples.

Chi-square, Student's $t$-test, and the Mann-Whitney $U$-test were used to compare groups. The effect of PCB and dioxin exposure on the neurological condition was investigated by a multiple linear regression analysis. The dependent variables were the neurological optimality score and the fluency cluster score at 18 months. The distribution of the neurological optimality score was skew to the left. The highest possible score is $\mathbf{5 7}$. In order to achieve normality, the neurological optimality score was transformed into:

$-\log (57.5-$ the neurological optimality score).

The independent variables in the regression analysis were the logarithmically transformed PCB and dioxin levels, social, perinatal and obstetrical variables from the obstetric optimality list, and the study centre. A $P$-value of 0.05 or less was considered significant.

\section{Results}

The study group consisted of 418 mother-infant pairs: 209 in the breast-feeding group and 209 in the formula-feeding group. On the basis of the neurological examination, 408 toddlers were classified as neurologically 'normal'. Nine children were categorized as 'mildly abnormal': mild hypertonia was found in six toddlers, one child showed non-fluent movements in several positions, one toddler had a poor variability of the motor functional repertoire, and in one case instability for the behavioural states was found during two independent sessions. One toddler had a hypertonic syndrome which was diagnosed as 'abnormal'. In the normal group, the median neurological optimality score was 48 (range: 34-55), whereas in the group classified as mildly abnormal or abnormal the median was found to be 42 (range: 38-45). Characteristics of the study group are presented in Table 1. Three maternal blood samples were missing. No cord blood samples could be obtained from 36 mother-infant pairs. For the analysis of PCB 118 in cord plasma, nine samples were missing. In human milk, representative dioxin, planar and non-planar PCB congeners were available in 176, 194 and 195 milk samples, respectively.

Table 2 presents the results of the regression analysis for the neurological optimality score. Neither PCB nor dioxin exposure via breast milk were associated with the neurological optimality score. The final model included education of the father, parity, study centre, and smoking of the father during pregnancy; and $\mathrm{EPCB}_{\text {cord }}$. The first three variables had about the same effect (regression coefficients $\beta=0.15$ ). The children of less educated fathers scored lower than the children of well educated fathers; the first-born children had a higher score than the second- or third-born 
Table 2

Regression analysis: neurological optimality score ${ }^{a}$

\begin{tabular}{lcc}
\hline Variable & $\begin{array}{l}\text { Regression coefficient } \\
\text { (standard error) }\end{array}$ & $P$-value (two-tailed) \\
\hline Constant & $-2.039(0.094)$ & \\
Education of the father $(0=$ low, $1=$ high $)$ & $0.135(0.046)$ & 0.004 \\
Parity $(0=$ first, $1=$ not first-born) & $-0.159(0.038)$ & 0.000 \\
Study centre $(0=$ Groningen, $1=$ Rotterdam) & $0.135(0.038)$ & 0.000 \\
Log $\left(\Sigma P C B_{\text {cond }} / 0.08\right)$ & $-0.149(0.049)$ & 0.003 \\
Smoking of the father $(0=$ no, $1=$ yes $)$ & $-0.402(0.130)$ & 0.002 \\
Log( $\left(\Sigma P C B_{\text {cord }} / 0.08\right) \times$ Smoking of the father & $0.200(0.078)$ & 0.011
\end{tabular}

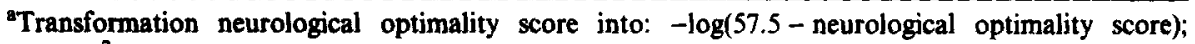
$n=373, R^{2}=0.14$.

children. The model also included a significant $(P=0.011)$ interaction between $\Sigma \mathrm{PCB}_{\text {cord }}$ and smoking of the father. To facilitate the interpretation of regression coefficients, we worked with $\log \left(\mathbf{L P C B}_{\text {cord }}\right)$ minus its minimal value $\log (0.08)$. With this definition, the regression coefficient of smoking of the father $(\beta=-0.402$, $P=0.002$ ) estimates the effect of smoking at the lowest $\Sigma P C B_{\text {cord }}$ exposure. Similarly, the coefficient for $\mathbf{\Sigma} \mathbf{P C B}_{\text {cord }}$ estimates the effect of $\mathbf{\Sigma P C B}_{\text {cord }}$ in the nonsmoking-father group. This effect was negative $(\beta=-0.149, P=0.003)$, in contrast to hardly any effect in the smoking-father group $(\beta=-0.051, P=0.404)$. The children of non-smoking fathers had the highest adjusted neurological optimality score in the presence of a low $\Sigma P{ } B_{\text {cord }}$ value. In the case of a high $\mathbf{\Sigma P C B}_{\text {cord }}$ value, the optimality score was similar to that of children of smoking fathers. Nearly the same results are obtained if $\Sigma \mathrm{PCB}_{\text {cord }}$ is replaced by $\Sigma \mathrm{PCB}_{\text {maternal. }}$.

Table 3

Regression analysis: fluency cluster score

Variable

Regression coefficient $P$-value (two-tailed)

(standard error)

$\begin{array}{lrr}\text { Constant } & 8.539(0.356) & \\ \begin{array}{l}\text { Type of feeding }(0=\text { breast-feeding, } 1=\text { formula- } \\ \quad \text { feeding) }\end{array} & -0.450(0.177) & 0.012 \\ \text { Log }\left(\Sigma P C B_{\text {cond }}\right) & -0.295(0.175) & 0.093 \\ \text { Parity }(0=\text { first, } 1=\text { not first-born }) & -0.394(0.168) & 0.020 \\ \text { Education of the father }(0=\text { low, } 1=\text { high }) & 1.352(0.293) & 0.000 \\ \text { Study centre }(0=\text { Groningen, } 1=\text { Rotterdam }) & 1.628(0.336) & 0.000 \\ \text { Education of the father } \times \text { Study centre } & -1.072(0.388) & 0.006\end{array}$

$n=373, R^{2}=0.15$. 
The size of the estimated prenatal PCB effect on the neurological optimality score is elucidated in the following example. A first-born toddler living in Groningen with a highly educated non-smoking father has an estimated neurological optimality score of 49.9 in case of a $\Sigma P C B_{\text {cord }}$ value at the 5 th percentile (i.e. 0.18 ) and a score of 47.9 in case of a $\mathrm{SPCB}_{\text {cord }}$ value at the 95 th percentile (i.e. 0.86 ). Thus, the difference is only two points.

The fluency cluster score was related to neither the $\mathbf{L P C B}_{\text {cord }}$ and $\mathbf{L P C B _ { \text { miaternal } }}$ concentrations nor to the $\mathrm{PCB}$ and dioxin levels in breast milk. Breast-fed children had a higher fluency cluster score compared to formula-fed children $(P=0.01$; Table 3).

\section{Discussion}

Prenatal PCB exposure had a small negative effect on the neurological condition of 18-month-old toddlers whose fathers did not smoke. Such an effect seemed to be blurred in children of fathers who smoked. No effect of lactational exposure to PCBs and dioxins through breast milk on neurological condition could be detected. In contrast, breast-fed children had a higher fluency cluster score compared to formula-fed children.

A negative effect of prenatal PCB exposure on psychomotor development was found by Rogan and Gladen [7,17] in North Carolina. They followed 802 children from birth through to 5 years of age by means of the Bayley - and McCarthy Seales. At 6, 12, 18 and 24 months of age, a significant relation between prenatal PCB exposure and a lower psychomotor performance was found, but at 3, 4, and 5 years of age, no effect of prenatal PCB exposure could be detected. PCB exposure via breast milk had no influence. Levels of PCB exposure in the USA are comparable to those in the Netherlands. It is important to realize that developmental tests and the developmental neurological examination measure different aspects of brain function. The Bayley - and the McCarthy Scales measure developmental levels at different ages quantitatively. The developmental neurological examination gives a qualitative appraisal of brain integrity, in which developmental age levels are unimportant.

In our study of newborns, we found that the combination of a high prenatal and high lactational exposure to PCBs and dioxins during the first 2 weeks after birth was associated with an increase in the prevalence of neurological non-optimality [5]. At 18 months, neurological differences could only be attributed to prenatal PCB exposure. It is difficult to relate the functions of the central nervous system in the neonatal period directly with those at 18 months, as they are generated by quite different brains. From the early stages of pregnancy until many years after birth, large morphological changes take place in the central nervous system, such as outgrowth and retraction of dendrites and axones, myelination, and synapse reorganisation. The effects of these maturational changes are reflected in the functional development of the child.

A possible explanation for the role of smoking of the father on the neurological condition at 18 months is a passive smoking effect. We prefer, however, to view this 
variable as a proxy variable of characteristics of the relevant environment. Smoking behaviour of the mother was not significantly related to the neurological optimality score, but we recorded the smoking behaviour of the mother only during pregnancy. It is possible that mothers temporarily stop smoking because of their pregnancy, whereas it is far less likely that fathers do.

The difference between the two study centres is probably due to differences between the two observers. We also found differences between the two centres/observers in our study of neonates [5]. The regression analysis adjusts for these effects. Nevertheless, the issue of the reliability of methods of assessment of neurological condition in healthy young children needs further attention.

The neurochemical mechanisms responsible for the neurotoxic effects of PCBs are not well understood. In animals, PCBs and dioxins have been found to affect dopamine [18-20] and thyroid hormonal metabolism [21,22]. In a subgroup of this study [23] and in another study concerning neonates [24], thyroid hormone status was not related to the neonatal neurological status $[25,26]$.

An effect of lactational exposure to PCBs and dioxins could not be detected at 18 months. Despite the fact that greater amounts of PCBs and dioxins are transferred via nursing than via placental passage, we found indications of a beneficial effect of breast-feeding. These results support the findings of Rogan and Gladen [27], who reported that cognitive development in breast-fed children from 2 through to 5 years of age was slightly better than in formula-fed children. In the present study, a beneficial effect was found on the fluency of complex movement patterns. The fluency of movements is an indication of the quality of brain function rather than of the level of development. This aspect of the quality of movements can be regarded as a reflection of the differentiation of cortex and basal ganglia function; cortical networks develop largely after birth, and also during the period of lactation.

Advantageous effects of breast-feeding on brain development are well documented [28-30], but the mechanism behind such beneficial effects remains unclear. Besides the socio-behavioural aspect of breast-feeding, the composition of human milk might be responsible. Maternal hormones like the thyroid stimulating hormone and other biologically active peptides reach the infant via breast milk. Long-chain polyunsaturated fatty acids seem to be essential for development of the brain [31-33]. They are present in breast milk, but are not in general added to term-infant formula milks.

In conclusion, transplacental PCB exposure is negatively related to the neurological condition in children at 18 months. No effect of postnatal exposure to PCBs and dioxins via breast milk could be detected. Despite the contamination of human milk with PCBs and dioxins, a beneficial effect of breast-feeding on the fluency of movements was found. This effect on the quality of brain function during development has not been reported before.

\section{Acknowledgements}

We thank F.A.J. Muskiet for his critical advice, Mrs A.A. Olinga for technical assistance, M.S. Hempel and M. Hadders-Algra for their help in composing the 
neurological optimality list, the midwives and the parents of the children for their co-operation. This work was supported by the Dutch Toxicology Research Promotion Programme and the Health Research Stimulation Programme.

\section{Appendix}

Criteria for the 57 items of the neurological optimality score at 18 months.

Item Criteria for optimality

\section{Prehemsion}

1. Mode of grasping

2. Posture arm/shoulder

3. Quality of arm/shoulder movements ${ }^{a}$

4. Posture hands/fingers

5. Adjustment hand-opening

6. Associated movements (hindering)

7. Quality of hand mobility

\section{Sitting}

8. Sitting (up)

9. Posture head/trunk/legs/feet/toes

10. Trunk rotation, spontaneous

11. Trunk rotation, elicited ${ }^{\mathbf{a}}$

12. Fluency of trunk movements ${ }^{2}$

13. Acceleration/deceleration ${ }^{*}$

\section{Crawling}

14. Symmetry of movements

15. Posture head

16. Coordination of arm-leg movements

17. Variability in speed

18. Fluency of trunk movements ${ }^{\mathrm{a}}$

\section{Standing}

19. Standing up/free

20. Variability in standing up

21. Posture head/arms/trunk/legs posture feet/toes

22. Distance between feet

23. Balance without movements

24. Balance with movements

25. Trunk rotation, spontaneous ${ }^{\mathrm{a}}$

26. Trunk rotation, elicited

27. Fluency of trunk movements ${ }^{a}$

28. Reaction to push against shoulders

\section{Walking}

29. Ability to walk

30. Fluency of trunk movements ${ }^{\mathrm{a}}$

31. Fluency of leg movements
Pincer grasp present in left and right hand

Normal, variable posture

Smooth

Normal, variable posture

Good

Absent or if present they do not hinder

Smooth

Can sit (up) without help

Normal, variable posture (head: centred and well-

adapted posture)

Trunk rotation present

Trunk rotation $>45^{\circ}$

Smooth

Smooth

No asymmetry

Centred and well-adapted

Coordinated arm-leg movernents

Variable speed

Non-fluent/smooth

Can stand up without help with object in both hands/stands free

Various ways of standing up

Normal, variable and well-adapted

Medium

No correction movements visible

No or small correction movements in the arms

Trunk rotation present

Trunk rotation present

Non-fluent/smooth

Good balance
Able to walk without help

Non-fluent/smooth

Non-fluent/smooth 


\section{Appendix (Continued)}

Criteria for the 57 items of the neurological optimality score at 18 months.

Item

Criteria for optimality

32. Reciprocal arm swing ${ }^{\mathrm{a}}$

33. Posture head/arms/trunk/legs/feet/toes

34. Gait width

35. Balance during walking

36. Abduction shoulders

37. Walking on tiptoe ${ }^{\mathrm{a}}$

38. Variability of speed

39. Manoeuvrability

40. Ability to avoid objects

\section{Present}

Normal, variable and well-adapted posture

Medium

Good balance, no correction movements needed

No abduction of the shoulders

No walking on tiptoe involuntarily

Variable speed

Changing direction in wide and sharp turns

Avoids obstacles adequately or steps on objects sometimes

Symmetrical and centred position

Smooth, symmetrical movements

No nystagmoid movements

Symmetrical present horizontally and vertically

Round, medium sized pupils/immediate reaction

Visual fields apparently intact

Visual acuity apparently intact

Quick and adequate reaction to sounds

Normal alert and symmetrical facial mobility

Absent

Normal, age-adequate speech and language development

Moderate resistance

Adequate for age

Medium range

Normal intensity

Medium threshold

No movements or plantar flexion of big toe

For descriptive details of the items, see Hempel [12].

${ }^{2}$ Included in the fluency cluster score.

\section{References}

[1] Jensen, A.A. (1987): Polychlorobiphenyls (PCBs), polychlorodibenzo-p-dioxins (PCCDs) and polychlorodibenzofurans (PCDFs) in human milk, blood and adipose tissue. Sci. Total Environ., 64, 259-293.

[2] Masuda, Y., Kagawa, R., Tokudome, S. and Kuratsune, M. (1978): Transfer of polychlorinated biphenyls to the foetuses and offspring of mice. Food Cosmet. Toxicol., 16, 33-37.

[3] Allen, J.R. and Barsotti, D.A. (1976): The effects of transplacental and mammary movement of PCBs on infant rhesus monkeys. Toxicology, 6, 331-340.

[4] Jacobson, J.L., Fein, G.G., Jacobson, S.W., Schwartz, P.M. and Dowler, J.K. (1984): The transfer 
of polychlorinated biphenyls (PCBs) and polybrominated biphenyls (PBBs) across the human placenta and into maternal milk. Am. J. Public Health, 74, 378-379.

[5] Huisman, M., Koopman-Esseboom, C., Fidler, V., Hadders-Algra, M., Paauw, C.G. van der. Tuinstra, L.G.M.Th. et al. (1995): Perinatal exposure to polychlorinated biphenyls and dioxins and its effect on neonatal neurological development. Early Hum. Dev., 41, 111-127.

[6] Rogan, W.J., Gladen, B.C., McKinney, J.D., Carreras, N., Hardy, P., Thullen, J. et al. (1986): Neonatal effects of transplacental exposure to PCBs and DDE. J. Pediatr., 109, 335-341.

[7] Rogan, W.J. and Gladen, B.C. (1991): PCBs, DDE, and child development at 18 and 24 months. Ann. Epidemiol., 1, 407-413.

[8] Prechtl, H.F.R. (1980): The optimality concept. Early Hum. Dev., 4, 201-205.

[9] Touwen, B.C.L., Huisjes, H.J., Jurgens-van der Zee, A.D., Bierman-van Eendenburg, Smrkovsky, M. and Olinga, A.A. (1980): Obstetrical condition and neonatal neurological morbidity. An analysis with help of the optimality concept. Early Hum. Dev., 4, 207-228.

[10] Prechtl, H.F.R. (1977): The Neurological Examination of the Full-term Newborn Infant, 2nd edn. Clinics in Developmental Medicine, No. 63. Heinemann, London.

[11] Zorge, J.A. van, Wijnen, J.H. van, Theelen, R.M.C., Olie, K. and Berg, M. van den. (1989): Assessment of the toxicity of mixtures of halogenated dibenzodioxins and dibenzofurans by use of TEF. Chemosphere, 19, 1881-1895.

[12] Hempel, M.S. (1993): The Neurological Examination for Toddler-age. Dissertation. University of Groningen, Groningen, Netherlands.

[13] Touwen, B.C.L., Hempel, M.S. and Westra, L.C. (1992): The development of crawling between 18 months and four years. Dev. Med. Child Neurol., 34, 410-416.

[14] Hempel, M.S. (1993): Neurological development during toddling age in normal children and children at risk of developmental disorders. Early Hum. Dev., 34, 47-57.

[15] Prechtl, H.F.R. (1990): Qualitative changes of spontaneous movements in fetus and preterm infant are a marker of neurological dysfunction. Early Hum. Dev., 23, 151-158.

[16] Ferrari, F., Cioni, G. and Prechtl, H.F.R. (1990): Qualitative changes of general movements in preterm infants with brain lesions. Early Hum. Dev., 23, 193-231.

[17] Gladen, B.C. and Rogan, W.J. (1991): Effects of perinatal polychlorinated biphenyls and dichlorodiphenyl dichloroethene on later development. J. Pediatr., 119, 58-63.

[18] Seegal, R.F., Bush, B. and Brosch, K.O. (1991): Comparison of effects of Aroclors 1016 and 1260 on non-human primate catecholamine function. Toxicology, 66, 145-163.

[19] Seegal, R.F. and Shain, W. (1992): Neurotoxicity of polychlorinated biphenyls: The role of orthosubstituted congeners in altering neurochemical function. In: The Vulnerable Brain and Environmental Risks, Vol. 2, pp. 169-195. Editors: R.L. Isaacson and K.F. Jensen. Plenum, New York.

[20] Shain, W., Bush, B. and Seegal, R.F. (1991): Neurotoxicity of polychlorinated biphenyls: structureactivity relationship of individual congeners. Toxicol. Appl. Pharmacol., 111, 33-42.

[21] Brouwer, A. and Berg, K.J. van den. (1986): Binding of a metabolite of $3,4,3^{\prime}, 4^{\prime}$ tetrachlorobiphenyl to transthyretin reduces serum vitamin $A$ transport by inhibiting the formation of the protein complex carrying both retinol and thyroxin. Toxicol. Appl. Pharmacol., 85, 301-312.

[22] Berg, K.J. van den, Zurcher, C. and Brouwer, A. (1988): Effects of 3,4,3',4'-tetrachlorobiphenyl on thyroid function and histology in marmoset monkeys. Toxicol. Lett., 41, 77-86.

[23] Pluim, H.J., Koppe, J.G., Olie, K., Slikke, J.W. van de, Kok, J.H., Vulsma, T. et al. (1992): Effects of dioxins on thyroid function in newborn babies. Lancet, 339, 1303.

[24] Koopman-Esseboom, C., Morse, D.C., Weisglas-Kuperus, N., LutkeSchipholt, I.J., Paauw, C.G. van der, Tuinstra, L.G.M.Th. et al. (1994): Effects of dioxins and polychlorinated biphenyls on thyroid hormone status of pregnant women and their infants. Pediatr. Res., 36(4), 468-473.

[25] Koopman-Esseboom, C., Huisman, M., Morse D.C., Touwen, B.C.L., Paauw, C.G. van der, Tuinstra, L.G.M.Th. et al. (1995): Newborns diagnosed as neurologically abnormal with relation to PCB/dioxin exposure and their thyroid hormone status. Dev. Med. Child Neur. (submitzed).

[26] Pluim, H.J. (1993): Dioxins - Pre- and Postnatal Exposure in the Human Newborn. Dissertation. University of Amsterdam, Amsterdam, The Netherlands. 
[27] Rogan, W.J. and Gladen, G.C. (1993): Breast-feeding and cognitive development. Early Hum. Dev., 31, 181-193.

[28] Fergusson, D.M., Beautrais, A.L. and Silva, P.A. (1982): Breast-feeding and cognitive development in the first seven years of life. Soc. Sci. Med., 16, 1705-1708.

[29] Lucas, A., Morley, R., Cole, T.J., Lister, G. and Leeson-Payne, C. (1992): Breast milk and subsequent intelligence quotient in children born preterm. Lancet, 339, 261-264.

[30] Lanting, C.I., Fidler, V., Huisman, M., Touwen, B.C.L. and Boersma, E.R. (1994): Neurological differences between 9 -year-old children fed breast-milk or formula-milk as babies. Lancet, 344 , 1319-1322.

[31] Martinez, M., Conde, C. and Ballabriga, A. (1974): Some chemical aspects of human brain development: II phosphoglyceride fatty acids. Pediatr. Res., 8, 93-102.

[32] Clandinin, M.T., Chappel, J.E., Leong, S., Heim, T., Swyer, P.R. and Change G.W. (1980): Extrauterine fatty acid accretion in infant brain: implications for fatty acid requirements. Early Hum. Dev., 4, 131-138.

[33] Uauy, R.D., Birch, D.G., Birch, E.E., Tyson, J.T. and Hoffman, D.R. (1990): Effect of omega-3 fatty acids on retinal function of very-low-birth-weight neonates. Pediatr. Res., 28, 485-492. 